\title{
NETWORK ANALYSIS FOR THE IMPROUEMENT OF FOOD SAFETY IN THE INTERNATIONAL HONEY TRADE
}

\author{
József Popp ${ }^{1}$, Anna Kiss ${ }^{2}$, Judit Oláh ${ }^{3 *}$, Domicián Mátée \\ Attila $\mathrm{Bai}^{5}$ and Zoltán Lakner \\ ${ }^{13344) 5}$ University of Debrecen, Hungary \\ ${ }^{2) 6}$ Szent István University, Hungary
}

Please cite this article as:

Popp, J., Kiss, A., Oláh, J., Máté, D., Bai, A. and Lakner, Z., 2018. Network Analysis for the Improvement of Food Safety in the International Honey Trad. Amfiteatru Economic, 20(47), pp. 84-98

\section{Article History}

Received: 22 September 2017

Revised: 19 October 2017

Accepted: 16 November 2017

\begin{abstract}
Honey, this relatively homogenous, hard to trace product, characterised by considerable international price differences, and often regulated by high tariff barriers, lends itself to economically motivated product adulteration. The adulteration of honey can undermine confidence in products as well as having adverse public health consequences. The aim of this research is to demonstrate the possibilities for the utilisation of network-based stochastic simulation methods to determine the proliferation of (accidentally or deliberately) polluted food products, using the example of the international honey trade network. The database for the analysis is based on the FAO dataset. The results of a network analysis of the global honey trade system highlight the scale-free character of the world's honey supply system. Focussing on backbone states and product flows, it is possible to determine the geographical distribution of polluted products as a function of the source of pollution. This information is important for the organisation of international trade control systems when contaminated products appear in a given state. The "polluted product transfer capacity" and the exposure of different states to polluted honey products can, in most cases, be efficiently forecast by the simultaneous application of different centrality measures and indicators.
\end{abstract}

Keywords: centrality measures, international trade, food safety, honey trade, scale free network, stochastic simulation, vulnerability analysis

JEL Classification : F14, F17, F61, L15, Q17

*Corresponding author, Judit Oláh - olah.judit@econ.unideb.hu 


\section{Introduction}

Although honey represents just a small part of the world's food sweetener production, it is widely present in almost all cultures and countries (FAO, 2015). The overwhelming majority of honey production is consumed in domestic markets, but there is an increasing tendency to export. In 2016 global honey production amounted to 1,704 thousand tonnes, and the global honey export was 569 thousand tonnes (UN Comtrade, 2017); however,since 2008 the growth in total honey output has failed to regain its upward trend. The foreign trade share of honey was ca. $12 \%$ of global output at the beginning of the 1960 s but this had increased to close to $35 \%$ of global production by 2016.China, the EU, Turkey, Argentina and Ukraine were the largest producers of honey with a 55\% share of global production in 2015 (FAO, 2017). China, South America and Central America and the Caribbean were the leading exporters of honey with a $65 \%$ share of world exports in 2015.The leading top ten importers of natural honey accounted for $72 \%$ of world imports. The USA and the EU are the top two importers.

Honey production is a small sector in the EU but essential in agriculture for pollinisation. The 0.7 kilograms per capita annual consumption of honey in the EU amounted to a total consumption of 360,000 tonnes in 2013 . The EU, with its $20 \%$ share of the total global consumption is the most important honey consumer worldwide, followed by China, the USA and Turkey (European Commission, 2017a).Table honey constitutes $75 \%$ of the honey market, while the remaining $25 \%$ is used as industrial honey (as an ingredient in food products). The consumption of monofloral varieties (acacia, clover, fir, pine etc.) is expected to grow relative to blended honey, mainly in the United Kingdom, Germany and France (European Commission, 2017b). Recently, organic honey has gained popularity and there is a price premium of up to $20 \%$ for certified organic honey. The self-sufficiency rate of the honey market in the EU is around 60\%. Production of honey is expected to decline in the future, although the EU remains the second largest global producer of honey after China. Romania has become the largest honey producer in the EU, and in 2015 produced 35,000 tonnes of honey, followed by Spain, with 32,200 tonnes and by Hungary, with 30,700 tonnes, together accounting for almost $40 \%$ of total EU production (European Commission, 2017a). Since 2011 the EU's honey exports have increased, amounting to 145,000 tonnes in 2015; however, just 18,000 tonnes of honey were sold to third countries. These numbers show that most of the honey export is intra-EU trade rather than extra-EU trade (UN Comtrade, 2017).

Honey imports to the EU increased to 200,000 tonnes in 2015. Honey suppliers from developing countries represented a $60 \%$ share of total honey imports (China had a $29 \%$ share). Other main honey exporter countries to the EU are Mexico, Argentina and Brazil. Until 2010 Argentina was the second largest supplier of honey to the EU, but in 2010 GMO pollen was found in Argentinean honey, leading to a decline in Argentinean exports directed to the EU. Germany, the UK and France are the biggest importing member states, absorbing about $50 \%$ of total imports. Intra-EU trade has increased between new and old member states (European Commission, 2017a).In the framework of the free trade agreement between the EU and the Ukraine, which came in to effect in 2016, a duty-free export quota of 5,200 tonnes of honey was assigned to the Ukraine, which is set to increase by another 800 tonnes by 2020. The customs-free export quota for Ukrainian honey is easily used up at the beginning of the year, at which point a $17 \%$ customs duty is imposed. 
The price of Ukrainian honey on the EU market is by $30-40 \%$ cheaper than EU-produced honey (UN Comtrade, 2017).

The aim of this study is to analyse the international honey trade network and determine the characteristic features of proliferation of the contaminated products within it. This paper is structured as follows: the first part outlines the development of the international trade, and the current food safety and authenticity problems of honey. The research methodology part determines the hypothesis of the work and describes the theoretical principles, as well as practical foundations of the current research based on the application of network analysis of international honey trade flows. The results section highlights the fact that the international honey trade can be considered a coherent, complex system. This is why the contaminated honey can spread very fast in the system, appearing on new, geographically distant markets. The most vulnerable parts of the network have been identified and the most important characteristic features of network indicators determined.

\section{Review of the scientific literature}

It is well documented that there are considerable food safety risks involved in honey consumption. These are microbiological (Mayara et al., 2017) as well as food chemical risks caused, for example, by residuals of plant protection chemicals (Chauzat et al., 2006), high heavy metal concentrations (Sánchez-Hernández et al., 2016), or radioactivity (Altekin et al., 2015).

One of the most important drivers of the international honey trade is the stagnating honey production in developed regions of the world. This phenomena can be explained by a longrange, persistent decline in honey bee colony numbers in Europe, as well as in the USA (Potts et al., 2010), due to the decreasing profitability of beekeeping (Aizen and Harder, 2009) and the collapse of the state subsidy system in the former Soviet states(Ellis and Munn, 2005).

Honey adulteration is as old as the honey trade itself (Johnston, 1942). The most important means of adulteration were concentrated must or date syrup. The adulteration of honey runs like a red line through the history of honey production, and as a Hungarian specialist declared at the end of $19^{\text {th }}$ century, "There is no other product which lends itself more to adulteration than honey" (Abróczy, 1896). This adulteration can take different forms and customary practices (Isopescu et al., 2017).

It is well-documented that there is a close, mutual relationship between the import-policies of the key market players. In 2008, US federal authorities started to investigate the laundering of Chinese honey carried out in order to evade antidumping duties. This investigation, called 'Honeygate', uncovered the largest food industry fraud in the USA(Phipps et al., 2015).The practice of re-labelling the product with the intent to hide the country of origin is a considerable problem in the case of honey imported into the US, and is referred to as "honey laundering" (Zach et al., 2012).

The complexity of the international honey trade necessitates the application of network science, which is why the conceptual framework for our analysis is network theory. We have considered the international trade in honey as a network. The nodes (hubs, vertices) of the network are the different states and other statistically registered theoretical units (sovereigns), while the trade flows of honey form the edges of the network. This approach 
is widely applied in studies of international trade (Chaney, 2014). There is an increasing importance of network-based approaches to food system analysis in general (Hueston, 2012; McDowell, 2017), and food safety-based analysis of supply systems in particular (Pinior et al., 2015). Ercsey-Ravasz et al. (2012) have proved by a graph theory-based food flux model analysis that the international agro-food trade network is a suitable vehicle for the rapid distribution of contaminated products, but it is extremely hard to trace the origin of products.

Nepusz et al. (2009) have developed a relatively easy to handle analytical tool based on the EU's Rapid Alert System for Food and Feed (RASFF).Based on RASFF they have identified Iran, China and Turkey as the most important transgressors with the largest number of alerts. Analysing the results of RASFF, Petróczi et al. (2010) highlighted that there are considerable differences between the alerting frequencies of the EU member states. In the opinion of Rortais et al. (2010) the network analysis of Medical Information System data on food borne diseases can be a valuable source of information, too. Beside the "official" sources of information the network analysis of community websites can supply a valuable input for the operation of early warning systems (De Quincey et al., 2009). Application of the big data approach further enhances these possibilities (Marvin et al. 2017). That is why in our study we propose a practice-based analysis of the international honey trade network and a relatively easy to handle tool for decision support systems involving the planning of food safety inspection systems.

\section{Research methodology}

In the framework of this research we intend to test the following proposals:

Hypothesis No. 1: The international network of honey can be characterised by a small number of central actors (countries) and a high number of peripheral nations. $\mathrm{H} 1_{\mathrm{a}}$ : This means that the central actors are linked in a densely-connected core, while the majority of participant countries are relatively atomised around the periphery of the network. $\mathrm{H} 1_{\mathrm{b}}$ : At the same time, there are some counties, which are local centres. It implies that these countries are extremely important in honey trade flow formation between different countries. The well-known "six degrees of separation" has long been the object of smalltalk and academic conversation (Heasely and Kleinberg, 2010), but accurate sociological research results highlight the abundance of relatively short paths between different individuals (Travers and Milgram, 1969). In other words, the network is a system of subnetworks with a scale free structure. The mean geodesic distance between nodes increases relatively slowly if we increase the number of nodes in the network (Porter, 2012). In Barabási's and Bonabeau's (2003) view, a scale free network can be characterised by a relatively low number of nodes, which have a high number of connections to other nodes. In a scale-free network the distribution of node linkages follows a power law distribution.

Hypothesis No. 2: The interconnectedness of the international honey trade network allows the possibility of a high speed proliferation of contaminated components. If we know the structure of the honey trade network, the hubs and the flow-intensities, we will be able to forecast the proliferation patterns of polluted (contaminated) honey. 
We have applied the data from the period between 2008 and 2014 because the application of a longer period could hide some structural breaks in the time series. The data for the investigations were obtained from the FAO statistical information system (FAO, 2017).

This study consists of three phases: in the first phase a conceptual model has been determined based on network analysis. In the second phase we have analysed the global honey trade; following this, we have applied a relatively simple network, which -as a consequence of the high level of concentration of the international honey trade -consists of 35 exporter and 48 importer countries. We have excluded importers which fall under the "unspecified area" heading and any actors which have reported just one export connection. In this way our matrix consists of 30 exporter and 47 importer countries. The network of the honey trade has been visualised and analysed by Cytoscape software (Shannon et al., 2003; Saito et al., 2012). This software is a widely used, free and complex tool of network visualisation and analysis (Chisanga et al., 2017). The countries are abbreviated by twoletter country codes from the International Organisation for Standardisation (ISO, 2017).The system simulation model for determining the proliferation patterns of contaminated products has been based on the following considerations:

- We have used quantitative data on exports, as opposed to data expressed in value (monetary) terms.

- A discrete-step approach has been applied in simulations, because this method is widely applied in supply chain system analysis (Borschev, 2013). In our model one time step is equal to one trade (export-import) transaction between two nodes. To put it in another way: one time step is enough to sell the contaminated product on the domestic market or export it to other states.

- The share of products consumed in the domestic market is assumed not to re-enter the international trade flow by any means. We further assumed that the share of domestic consumption of imported products is equal to the honey production/domestic consumption ratio. We have approximated the distribution of flows by a normal distribution even if in $32 \%$ of cases (country-country pairs) the approximation by another distribution (in $18 \%$ log-normal, $12 \%$ uniform) has given a better fit because, based on the classic central limit theorem, with an increasing number of observations a normal distribution would be generated (of course this cannot be realised in practice as a consequence of the considerable changes in the socio-economic environment) (Brown, 1971). Originally, this postulate was applied to independent variables, but as the latest results have proved, similar results are obtained for variables with autocorrelative processes (Cohen and Lindner, 2013).

The conceptual model of the proliferation of contaminated products is summarised in figure no. 2 .

Mathematically, based on two pieces of information - on the expected value of the honey trade flow between each country pair and its standard deviation - we have generated a matrix of honey flows $(\underline{\underline{H}})$. Each $\varepsilon_{i, j}$ element of this matrix represents a realisation of a stochastic process at $t_{\mathrm{th}}$ time period. We have multiplied this matrix with a vector $(p)$, the $n$ 1 element of this vector being 0 , one element being the quantity of polluted honey product. For simplicity, the quantity of this contaminated honey has been determined as 1000 units. Multiplying $\underline{\underline{H}} b y \underline{p}$ we can determine the distribution of contaminated products arriving from an arbitrary country. The process of this calculation is presented in figure no. 1. 
The proliferation of contaminated products in the network has been visualised by combining a heatmap technique (Deng et al., 2014) with dendogram clustering (Galili, 2015).
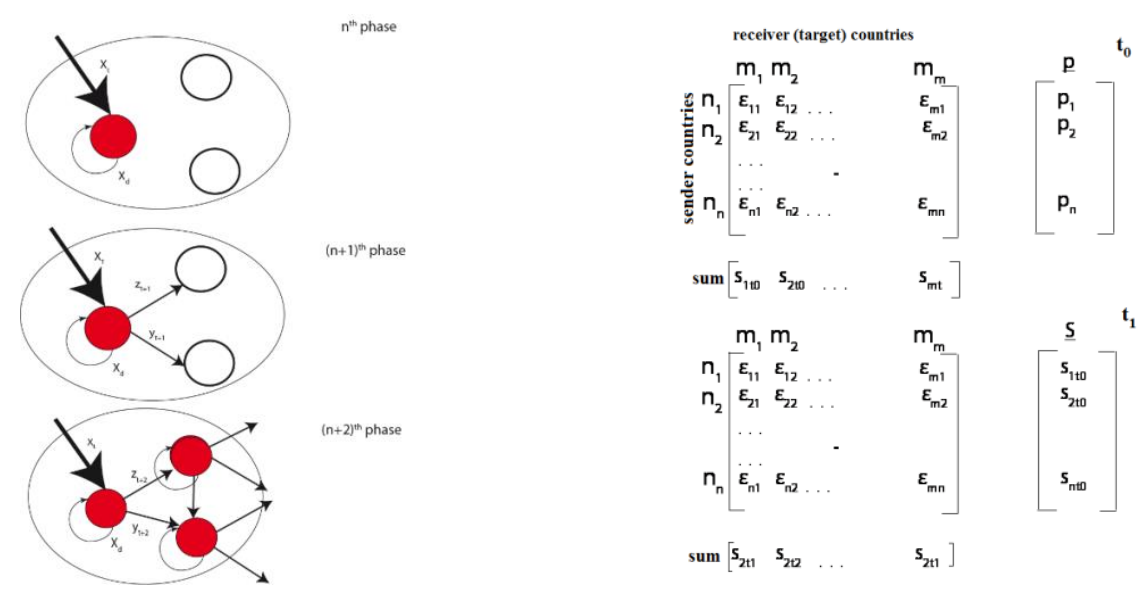

Figure no. 1: Conceptual and mathematical model of the proliferation of contaminated honey between different countries

Source: Authors' own construction, based on FAO (2017) statistical information system

\section{Results}

The global trade network of honey consists of 212 nodes, which means that practically all states and sovereign entities participate in the trade (figure no.2).

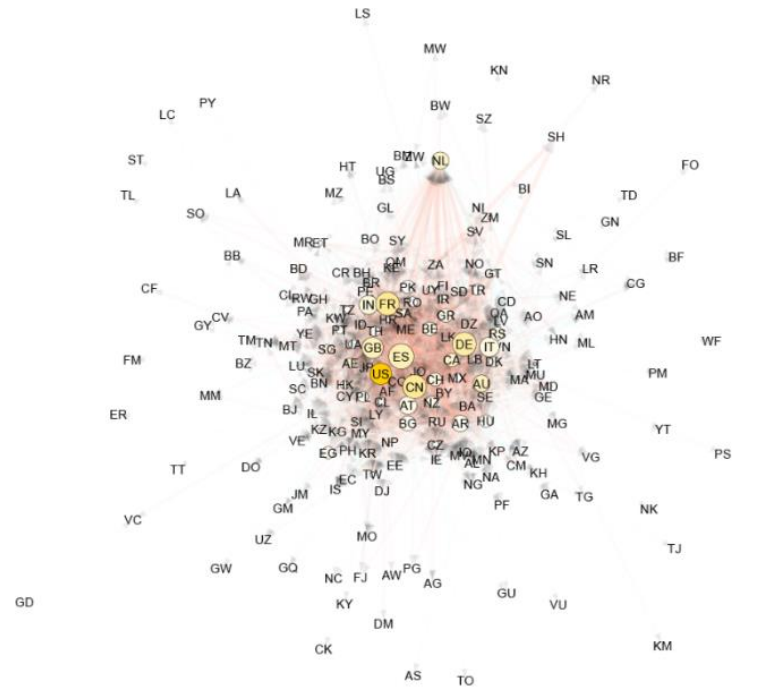

Figure no. 2: The world trade flow of honey

Source: Authors' own construction, based on FAO (2017) statistical information system 
This fact highlights the global character of honey consumption. The characteristic path length (Wang and Chen, 2003) is no more than 2.13, which shows the high level of connectedness in the network. The outdegree distribution follows a power low (figure no.3): the outdegree can be approximated by a $y=11.427 \mathrm{x}^{-0.538}$ equation $\left(\mathrm{r}^{2}=0.671\right)$. This fact supports the scale-free distribution hypothesis for the global system of the honey trade (figure no. 3).

The distribution of average path length

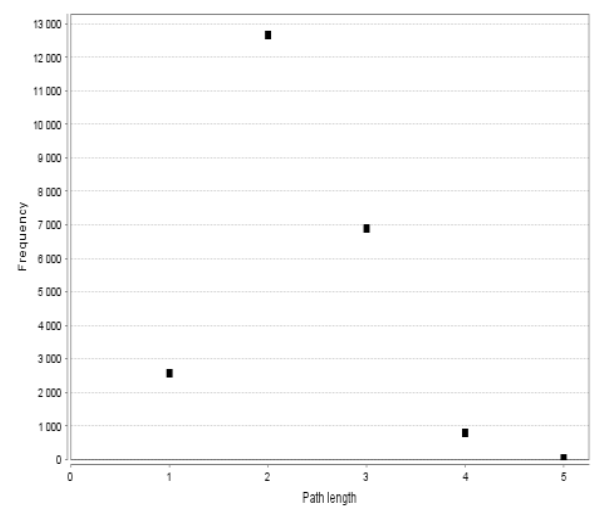

The outdegree distribution

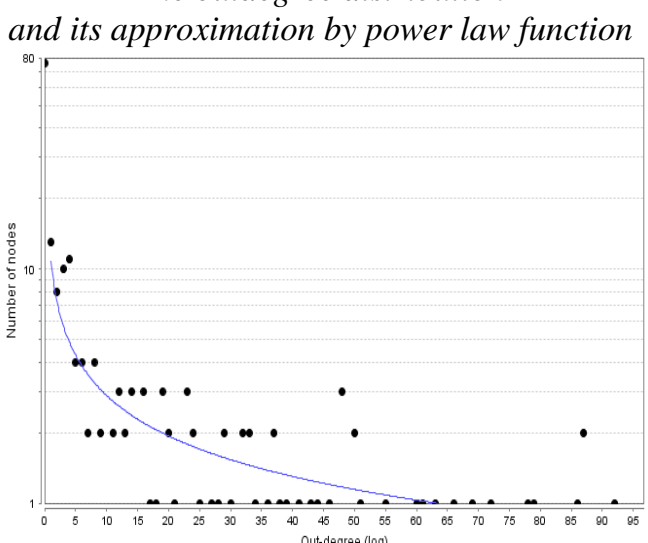

Figure no. 3: Some characteristic features of the world honey trade network

The circles are proportional with the outdegree, the line-thickness with the logarithm trade flow, and the circle colour with the betweenness centrality of the states

The majority of trade flows can be characterised by a relatively low value. Analysing the distribution of trade flows, this is even more obvious (figure no.4). The total network of the honey trade is unsuitable for analysis, which is why we have selected the most important trade flows based on the data for the period 2008-2014, representing $80 \%$ of the global honey trade. The circles are proportional with the outdegree, the line-thickness with the logarithm trade flow, and the circle colour with the betweenness centrality of the states.

To determine the main pipeline of the world honey trade network, edge betweenness is the most suitable indicator, because this gives information on the number of the shortest paths that go across an edge in a network (Yoon et al., 2006). In our case the path is the GermanDanish and the German-Spanish trade. In the case of these flows the edge betweennesses are 38 and 43, respectively. This means that these trade flows are extremely important. From the point of view of vulnerability this flow is the most critical. As a summary it can be stated that even the simplest methods of network analysis are suitable ways to determine the most vulnerable parts of the international trade network, which can be characterised by a small-world phenomenon, supporting Hypothesis No.1. 


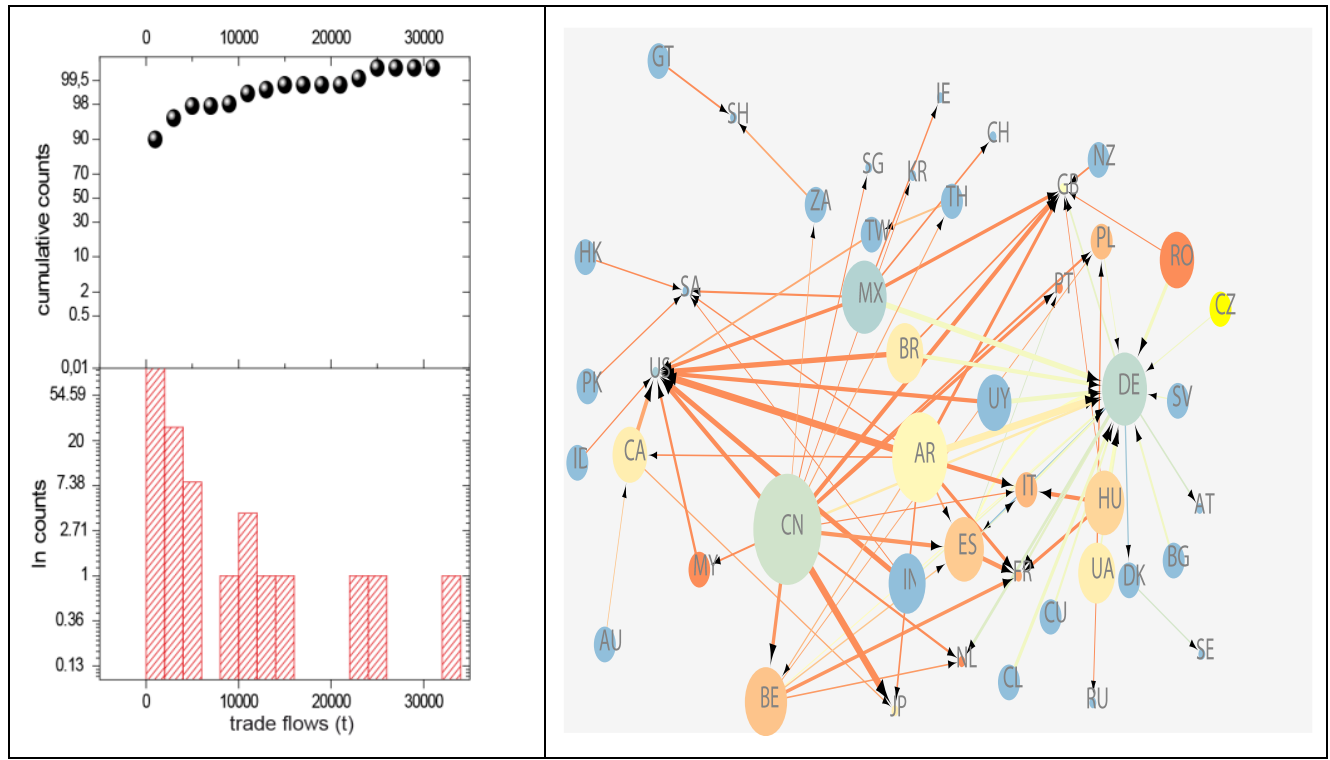

Figure no. 4: The concentration of the international honey trade (left) and its backbone (right)

Source: Authors' own construction, based on FAO (2017) statistical information system

Analysing the results of simulations to determine contaminated products in the network in different stages (figure no. 5), it is obvious that in the first stage of the arrival of a contaminated product in the network there are considerable differences between the countries concerned. Here, in the figure no. 5 the sources are in the rows and the targets (receivers) in the columns, too. The most vulnerable countries are Germany, the United States and the United Kingdom, because in most cases the contaminated products appear in these countries. The two Mediterranean importers, Italy and France are rather similar to each other. From this it follows that if, for example, a notification on contaminated honey from Italy arrives in the RASFF system, it is almost certain that this contaminated product will appear on the shelves of French supermarkets, too. An alert from Germany does not convey much information on the possible source of contamination because Germany's honey imports are quite diversified. At the same time, an alert from Greece could be an indication of the influx of contaminated honey from Thailand or Bulgaria. The figure no. 5 highlights the central role of mainland China in the global honey supply network; obviously, a contaminated product-shipment can cause considerable proliferation of polluted products in numerous countries. It is clear that Germany is the big turntable (in household technology: the "Lazy Susan") of the European honey trade network: from Germany the contaminated product arrives in the United Kingdom, Italy, France, the Netherlands, Spain, Belgium, Austria, Switzerland and Denmark. From Belgium the potentially contaminated product arrives in Spain or Saudi Arabia.

In the second stage of proliferation the situations in Austria, Denmark, Spain, Italy, Portugal, the UK and France show a high degree of similarity. From this it follows that if contaminated honey appears in any of these countries it is worth intensifying the food safety control of products. Germany, as a country with diversified import sources, differs 
considerably from other member states of the EU. It is worth highlighting the similarity between Austria and Denmark, as well as that between France and Switzerland.

In the third stage we experience a considerable proportion of contaminated products in the exports of EU-member states, as well as the USA and Japan. Interestingly, a high concentration of contaminated products appeared in Portugal, and - rather unexpectedly in Ukraine. This means that Ukraine plays the role of bridge-state. It is worth highlighting that while there appears to be a rather limited quantity of honey exported directly from Ukraine, in second and third stage of the re-export of contaminated honey Ukraine is an important source-country, which is able to export a high level of contaminated products in the second stage to Germany, Saudi Arabia, Ireland and India, as well as to the USA, France, Switzerland, Belgium and the United Kingdom. It is very interesting that the third stage of the international trade in contaminated products is concentrated in a relatively small number of countries. In this stage of the import of contaminated honey to Germany the two South American countries, Chile and Argentina, play an important role.

From the facts presented in this section it is very important to highlight, that: (1) the consequences of the appearance of contaminated honey products can have a long-lasting effect on the international honey trade, because the importing countries are in numerous cases also important players in the export of honey, which is why the contaminated products will appear in their imports. The greater the role of a country in the international honey trade, the higher the possibility that a receiver country will become a contaminated product sender country. (2) Based on an analysis of the export-import network structure, it is possible to identify the potential sources of proliferation. As a consequence of the complexity of the network, some - relatively marginal - market players can become important sources of contaminated products (e.g. Ukraine).

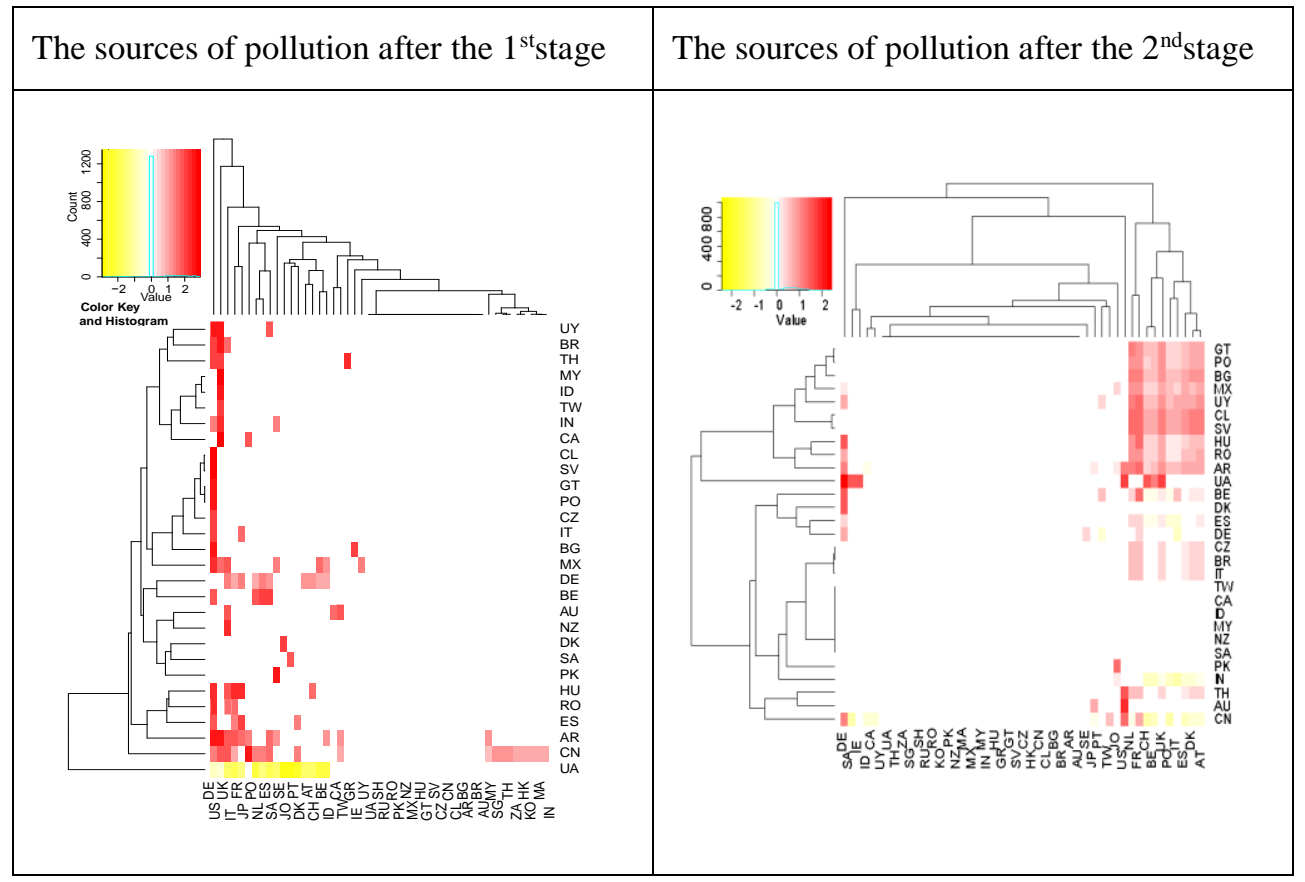




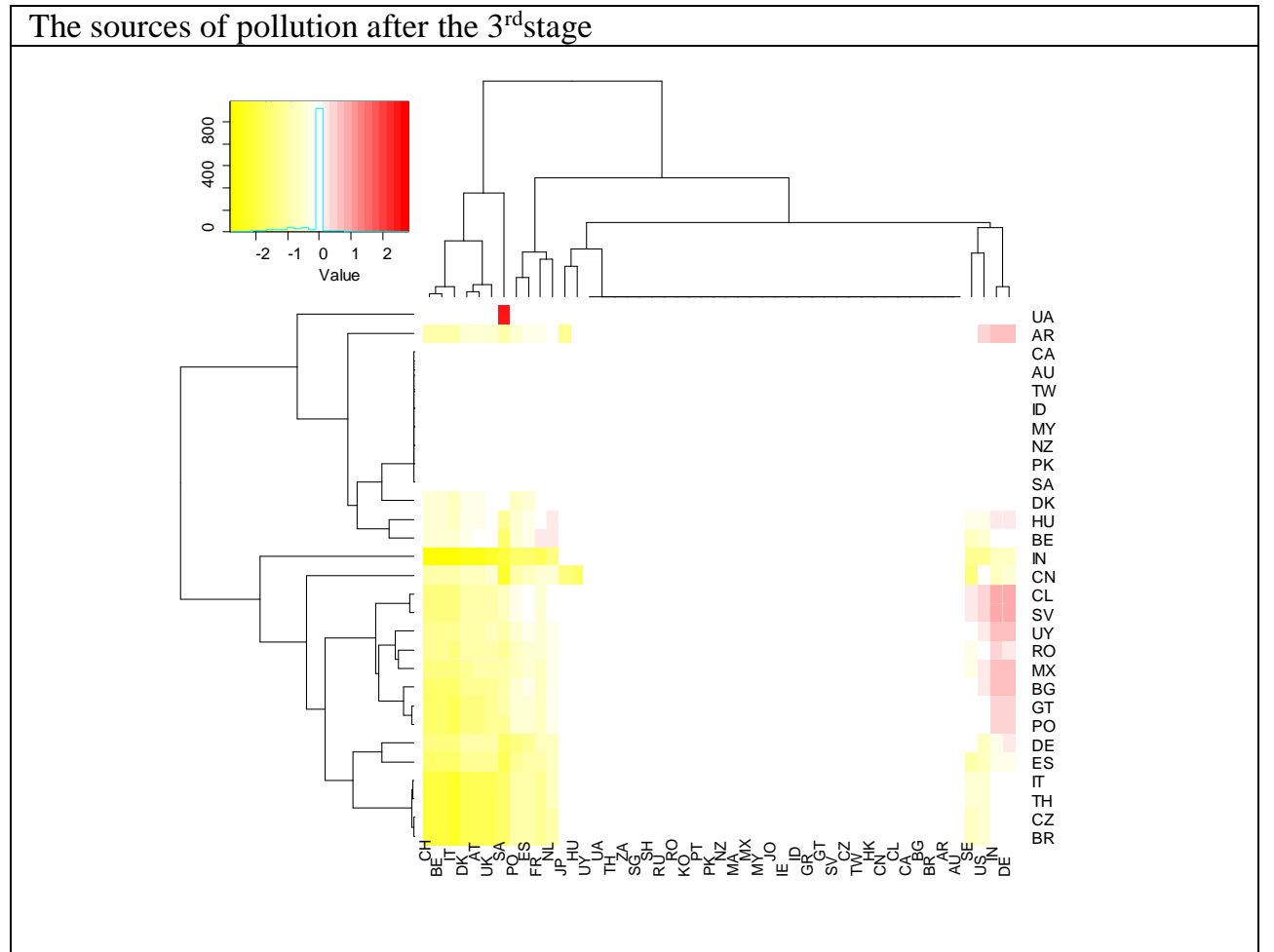

Figure no. 5: The appearance of contaminated products in different stages in the exports of different countries

Source: Authors' own calculation, based on a conceptual model created by the authors ( $a$ more detailed explanation is given in the article)

In the last phase of our analysis we have tested the stochastic relationships between the network position of countries described by different indicators of centrality and their behaviours in the trade in contaminated honey products. We have applied different centrality indicators because there is a relatively low correlation between different metrics of node centralities. This fact highlights that the different indicators furnish substantially different information on the position of network nodes.

Having investigated the transfer capacity of polluted products to other states (e.g. after the first stage) we can, in most cases, determine a significant multivariable linear regression equation between different measures of the centrality of "sending" countries and the quantity of polluted products transferred (Table no. 1). We have applied a stepwise regression method to filter the heteroscedasticity between independent variables (Antonakis and Dietz, 2011). In most cases the outdegree and closeness centrality have been significant parts of the equations but the control centrality measure has been performing well, too. This fact provides firm support for intuitive estimations and naive expectations; the nodes (states) in a more central position are capable of forecasting the quantity of contaminated products. 
Table no. 1: Multivariable regression coefficients for determining the "polluted products transfer capacity" of different states

\begin{tabular}{|l|l|l|l|l|l|l|l|}
\hline & Average & Between- & Close- & Cluste- & outdegree & control & $\mathbf{R}^{\mathbf{2}}$ \\
\hline Argentina & & & & & 0.892 & & 796 \\
\hline Belgium & & & & & 0.425 & & 0.180 \\
\hline Brazil & & & & & 0.651 & 0.234 & 0.489 \\
\hline Bulgaria & & & 0.287 & & 0.815 & & 0.804 \\
\hline Chile & & & 0.287 & & 0.815 & & 0.646 \\
\hline Czech Republic & & 0.815 & & & 0.287 & & 0.646 \\
\hline India & & & & & 0.466 & 0.301 & 0.312 \\
\hline Mexico & & & 0.159 & & 0.902 & & 0.778 \\
\hline Poland & & & 0.287 & & 0.815 & & 0.246 \\
\hline Romania & 0.259 & & & & 0.872 & & 0.718 \\
\hline
\end{tabular}

Note: *Pan and $\mathrm{Li}, 2014$

If we apply a similar method to determine the exposure of different states (e.g. the total quantity of contaminated products after the sixth stage) it is possible to estimate the exposure of contaminated products based on the network position (Table no. 2). In this case the control centrality measure performs extremely well. This is in line with the results of Liu et al. (2012), who emphasise the deep relationship between the hierarchical structure of the network and control centrality.

Table no. 2: Multivariable regression coefficients for determining the exposure of different states

\begin{tabular}{|l|c|c|c|c|c|r|}
\hline & $\begin{array}{c}\text { Average } \\
\text { shortest } \\
\text { path } \\
\text { length }\end{array}$ & $\begin{array}{r}\text { Close- } \\
\text { ness }\end{array}$ & $\begin{array}{r}\text { Cluste- } \\
\text { ring }\end{array}$ & outdegree & $\begin{array}{r}\text { control } \\
\text { centra } \\
\text { lity* }\end{array}$ & $\mathbf{R}^{2}$ \\
\hline Canada & 0.306 & & & & 0.702 & 0.568 \\
\hline Chile & & & & -0.312 & -1.092 & 0.565 \\
\hline China mainland & & & & -0.312 & -1.092 & 0.595 \\
\hline Taiwan Province of China & & 0.292 & & & 0.816 & 0.632 \\
\hline Germany & 0.377 & & & & 0.65 & 0.446 \\
\hline Poland & & & 0.293 & & 0.825 & 0.663 \\
\hline
\end{tabular}

Note: ${ }^{*}$ Pan and $\mathrm{Li}, 2014$

\section{Conclusion and discussion}

Honey is a global product, the international trade of which is boosted by the stagnation or decline in honey production in developed states, and increasing production in developing countries. The international market for honey is a rapidly evolving, dynamic system. This system can be analysed in an efficient way by network analysis. 
Our results have supported $\mathrm{H} 1$, because the international trade in honey can be characterised by a few hubs, around which there are numerous, relatively peripheral states. That is why the trade can be considered a scale-free network.

The hubs (nodes) of the network are the different countries and the edges of the networks are the trade flows of honey. This network can be described as a scale-free network because there are considerable differences between the relative importance of the hubs. The majority of hubs are rather peripheral, but some countries play a central role in product flows. The identification of local centres and the most important trade flows is critical to determine the most vulnerable parts of the network (Ślusarczyk, 2017). In this complex network a centrality position can be attributed to a node if the node is a very important exporter of products (e.g. China) or is an international turntable of products, like Germany. The most important (and hence the most vulnerable) product flows are the German-Danish and German-Spanish trade flows. This can be explained by the high centrality of these European countries. From this it follows that in the case of the emergence of contaminated products in this channel a Europe-wide honey-related food safety problem can be expected.

Based on a historic time-series of inter-state product flows, the dynamics of the network can be modelled. This is essential for forecasting the proliferation of contaminated products from one country to another. The results of a discrete-event simulation of product-flows support the $\mathrm{H} 2$ hypothesis, highlighting the fact that in a globalised world geographical proximity cannot be applied for forecasting the emergence of contaminated products (Kovács and Kot, 2016). The most vulnerable parts of the network are the big importer countries (e.g. Germany) but the hubs of proliferation may be countries characterised by high export-import ratios (e.g. the Netherland). The simulation-based analysis of contaminated honey flows offers a relatively cheap and easy-to-use method of forecasting the emergence of contaminated products in a trade network. Unlike traditional emergency management systems this approach offers a possibility for targeted food safety intervention in countries which are presumed to be exposed to contaminated products.

In further research it would be highly desirable to combine the results of modelling with the actual data obtained from the RASF system, but in the unanimous opinion of experts and public servants working with this system the current mechanism cannot be used for this purpose because there are considerable differences between the "rigidity" of national food safety systems, depending on the quantity of resources allocated to each food safety inspection system. Last, but not least, it should be underlined that the considerable distortions in the free trade of goods caused by specific tariffs and different value-added taxes are the hotbeds of product alternation and falsification. If these tariff- and non-tariff barriers could be eliminated, there is a high chance of a considerable decrease in illegal food trade and product alternation. However, the analysis of these problems goes well beyond the scope of the current study

In summary it can be stated that based on different network centrality indicators, the exposure of countries to contaminated honey products can be estimated with relatively high precision. This fact should encourage an even wider application of network analysis methods for the upgrading and further sophistication of international food safety systems. Our investigations highlight the fact that there is a close connection between different states (nodes), which is why (1) it is relatively easy to determine the most vulnerable parts (flows) of the honey trade; (2) there are some easily-identifiable centres (local hubs) of the honey trade; and (3) the understanding of the mechanism of network-flows help to forecast the 
proliferation patterns of contaminated products. In this way network analysis is an important tool for planning prevention systems. In our globalised world, these focussed systems are much more efficient than the traditional "quarantine-like" trade restriction solutions.

\section{Acknowledgments}

Supported by the ÚNKP-17-4 New National Excellence Program of the Ministry of Human Capacities.

\section{References}

Aizen, M.A. and Harder, L.D., 2009. The global stock of domesticated honey bees is growing slower than agricultural demand for pollination. Current Biology, 19(11), pp.915-918.

Altekin, E., Dizman, S. and Keser, R., 2015. Radioactivity and Heavy Metal Concentrations in Various Honey Samples. Journal of Environmental Protection and Ecology, 16(2), pp. 716-722.

Alvarez-Suarez, J.M., Tulipani, S., Romandini, S., Bertoli, E. and Battino, M., 2010. Contribution of honey in nutrition and human health: a review. Mediterranean Journal of Nutrition and Metabolism, 3(1), pp.15-23.

Antonakis, J. and Dietz, J., 2011. Looking for validity or testing it? The perils of stepwise regression, extreme-scores analysis, heteroscedasticity, and measurement error. Personality and Individual Differences, 50(3), pp.409-415.

Barabási, Bya-Ls. and Bonabeau, E., 2003. Scale-free. Scientific American, 288(5), pp.5059.

Borschev, A., 2013. The big book of simulation modelling. Multimethod Modeling with AnyLogic 6. San-Francisco: AnyLogic North America.

Brown, B.M., 1971. Martingale central limit theorems. Annals of Mathematical Statistics, 42(1), pp.59-66

Chaney, T., 2014. The network structure of international trade. American Economic Review, 104(11), pp.3600-3634.

Chauzat, M-P., Faucon, J-P., Martel, A-C., Lachaize, J., Cougoule, N. and Aubert, M., 2006. A survey of pesticide residues in pollen loads collected by honey bees in France. Journal of Economic Entomology, 99(2), pp.253-262.

Chisanga, D., Keerthikumar, S., Mathivanan, S., and Chilamkurti, N., 2017. Network Tools for the Analysis of Proteomic Data. Proteome Bioinformatics, 12(2), pp.177-197.

Cohen, S. and Lindner, A., 2013. A central limit theorem for the sample autocorrelations of a Lévy driven continuous time moving average process. Journal of Statistical Planning and Inference, 143(8), pp.1295-1306.

Crane, E., 1999. Recent research on the world history of beekeeping. Bee World, 80(4), pp.174-186.

Deng, W., Wang, Y., Liu, Z., Cheng, H. and Xue, Y., 2014. HemI: a toolkit for illustrating 
heatmaps. PLoS one. 9(11), e111988.

De Quincey, E., and Kostkova, P., 2009. Early warning and outbreak detection using social networking websites: The potential of twitter. In: ICST, International Conference on Electronic Healthcare.Second International ICST Conference, eHealth 2009. Istanbul, Turkey, 23-15 September 2009. s.1: Springer.

Ellis, J.D. and Munn, P.A., 2005. The worldwide health status of honey bees. Bee World, 86(4), pp.88-101.

European Commission, 2017a. Eurostat Comext. [online] Available at: <http://epp.eurostat.ec.europa.eu/newxtweb/> [Accessed 13 June 2017].

European Commission, 2017b. RASFF - Food and Feed Safety Alerts. [online] Available at: 〈https://ec.europa.eu/food/safety/rasff_en> [Accessed 13 June 2017].

Ercsey-Ravasz, M.r., Toroczkai, Z.n., Lakner, Z. n., and Baranyi, J., 2012. Complexity of the international agro-food trade network and its impact on food safety. PloS one, 7(5), e37810.

FAO, 2017. Faostat electronic database. [online] Available at: <https://www.faostat.org> [Accessed 13 June 2017].

Galili, T., 2015. Dendextend: an R package for visualizing, adjusting and comparing trees of hierarchical clustering. Bioinformatics, 31(22), pp.3718-3720.

Heasely, D. and Kleinberg, J., 2010. Networks, crowds, and markets. Reasoning about a highly connected world. Cambridge: Cambridge University Press.

Holme, P. and Kim, B.J., 2002. Growing scale-free networks with tunable clustering. Physical Review E, 65(2), 026107.

Hueston, W. and McLoad, A., 2012. Overview of the global food system: Changes over time/space and lessons for future food safety. Improving Food Safety through a One Health Approach. Washington: National Academies Press.

ISO, 2017. Complete List of Country \& Dialing Codes. [online] Available at: <http://www.worldatlas.com/aatlas/ctycodes.htm> [Accessed 13 June 2017].

Kovács, G. and Kot, S., 2016. New logistics and production trends as the effect of global economy changes. Polish Journal of Management Studies, 14(2), pp.115-126.

Marvin, H.J.P., Janssen, E. e. M., Bouzembrak, Y., Hendriksen, P.J.M., and Staats, M., 2017. Big data in food safety: An overview. Critical Reviews in Food Science and Nutrition, 57(11), pp.2286-2295.

Mayara, S.S., Rabadzhiev, Y., Eller, M.R., Iliev Ilia Ivanova, I. and Weyder, C., 2017. Microorganisms in Honey. In: A. De Toledo, ed. 2017. Honey Analysis. Madrid: InTech.

McDowell, T. C., 2017. The complexity of the international food industry. International Journal of Society Systems Science, 9(1), pp.1-28.

Moinde, J., 2016. The status and future prospects of honeybee production in Africa. Bulletin of Animal Health and Production in Africa, 64(1), pp.169-182.

Nepusz, T.S., Petrółczi, A. and Naughton, D P., 2009. Network analytical tool for monitoring global food safety highlights China. PLoS one, 4(8),e6680.

Petróczi, A., Taylor, G., Nepusz, T., and Naughton, D.P., 2010. Gate keepers of EU food safety: Four states lead on notification patterns and effectiveness. Food and Chemical 
Toxicology, 48(7), pp.1957-1964.

Phipps, R., Daberkow, S., Bryant, V., García, N. and Phipps, P., 2015. Honey Marketing for the Commercial Beekeeper. In: Ed. Joe M. Graham, ed. 2015. The Hive and the Honey Bee. Hamilton IL: Dadant \& Sons. pp.607-626.

Pinior, B., Conraths, F.J., Petersen, B. and Selhorst, T., 2015. Decision support for risks managers in the case of deliberate food contamination: the dairy industry as an example. Omega, 53(1), pp.41-48.

Pokhrel, S., 2009. Comparative benefits of beekeeping enterprise in Chitwan, Nepal. Journal of Agriculture and Environment, 10, pp.46-59.

Porter, M.A. 2012. Small-world network. Scholarpedia, 7(2), pp.1739.

Potts, S.G., Biesmeijer, J.C., Kremen, C., Neumann, P., Schweiger, O. and Kunin, W.E., 2010. Global pollinator declines: trends, impacts and drivers. Trends in Ecology \& Evolution, 25(6), pp.345-353.

Rortais, A.s., Belyaeva, J., Gemo, M., Van der Goot, E., and Linge, J.P., 2010. MedISys: An early-warning system for the detection of (re-) emerging food-and feed-borne hazards. Food Research International, 43(5), pp.1553-1556.

Saito, R., Smoot, M.E., Ono, K., Ruscheinski, J., Wang, P-L., Lotia, S., Pico, A.R., Bader, G. D. and Ideker, T., 2012. A travel guide to Cytoscape plugins. Nature Methods, 9(11), pp.1069-1076.

Shannon, P., Markiel, A., Ozier, O., Baliga, N.S., Wang, J.T., Ramage, D., Amin, N., Schwikowski, B. and Ideker, T., 2003. Cytoscape: a software environment for integrated models of biomolecular interaction networks. Genome Research, 13(11), pp.2498-2504.

Ślusarczyk, B., 2017. Prospects for the shared services centers development in Poland in the context of human resources availability. Polish Journal of Management Studies, 15(1), pp.218-231.

Travers, J. and Milgram, S. 1969. An experimental study of the small world problem. Sociometry, 32(4), pp.425-443.

Wang, X.F. and Chen, G., 2003. Complex networks: small-world, scale-free and beyond. IEEE Circuits and Systems Magazine, 3(1), pp.6-20.

Yoon, J., Blumer, A. and Lee, K., 2006. An algorithm for modularity analysis of directed and weighted biological networks based on edge-betweenness centrality. Bioinformatics, 22(24), pp.3106-3108.

UN Comtrade Database, 2017. 2015 International Trade Statistics Yearbook. [online]. Available at: 〈http://comtrade.un.org> [Accessed 13 June 2017].

Zach, L., Doyle, M.E., Bier, V. and Czuprynski, C., 2012. Systems and governance in food import safety: A US perspective. Food Control, 27(1), pp.153-162. 